$11-2019$

Interprofessional education: The way forward in health profession education

Kanza Muzaffar

Rehana Rehman

Salman Siddiqi

Follow this and additional works at: https://ecommons.aku.edu/pakistan_fhs_mc_bbs

Part of the Life Sciences Commons 
LETTER TO THE EDITOR

\section{Interprofessional Education: The Way Forward in Health Profession Education}

Kanza Muzaffar, Rehana Rehman, Hasan Salman Siddiqi

Madam, An essential component for preparing healthcare students to provide improved care to the patients is to provide them with interprofessional education (IPE). ${ }^{1}$ Centre for the Advancement of Interprofessional Education (CAIPE) defines IPE as "occasions when students from two or more professions in health and social care learn together during all or part of their professional training with the object of cultivating collaborative practice for providing patient-centered care".2 The cumulative effect of inter professional teamwork has shown to decrease the cost of healthcare, decrease duration of patient stay at the hospital and reduce medical errors, which ultimately leads to enhanced patient care quality. ${ }^{1}$

Developing, initiating and implementing an IPE curricula in an institution can be challenging if one or more of the core ingredients is missing. ${ }^{1}$ Some of the key elements that are required to develop an IPE are summarised in Figure.

Interprofessional Education Consortium (IPEC) has identified four core competencies that are necessary for implementing IPE, which includes:

A. values and ethics

B. roles and responsibilities

C. communication skills

D. teams and teamwork. ${ }^{3}$

Small-group discussions, case based learning and roleplays are few examples of the methods that are employed as an interactive IPE learning tool for the students. The concept of IPE also encourages students to learn values of different disciplines for a better understanding of interdisciplinary practice. 4

Numerous international organisations including the World Health Organization (WHO) have expressed their support for IPE. ${ }^{1}$ Following are some of the examples of IPE implementation in Pakistan:

In 2005, a cross-sectoral interprofessional collaboration was established and demonstrated during the devastating earthquake that struck northern Pakistan, whereupon Department of Biological and Biomedical Sciences, Aga Khan University, Karachi, Pakistan.

Correspondence: Kanza Muzaffar. e-mail: kanza.muzaffar@aku.edu

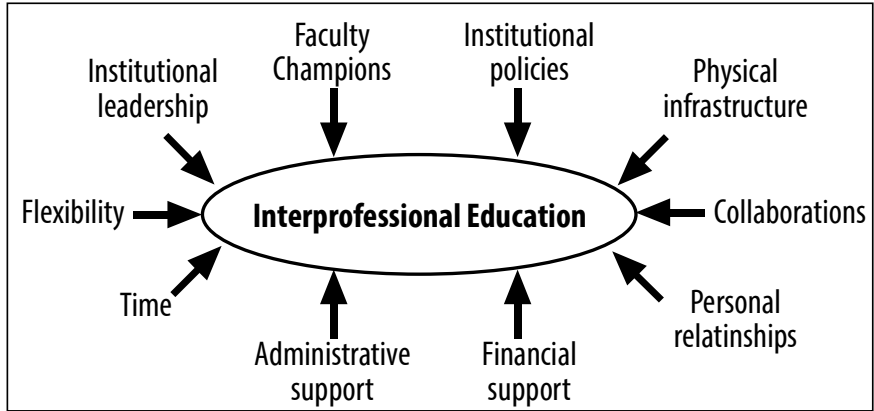

healthcare professionals and members of different professions joined forces to provide aid to the injured. 5 In Aga Khan University Hospital (AKUH) Karachi, Diploma in Dental Hygiene (DDH) programme has been designed by the departments of Basic Sciences, Dentistry and Educational Development (DED) which ultimately lead to a better and improved care of dental patients. DED has conducted a series of workshops by professionals that offers an insight to IPE, which were attended by students and professionals from varied healthcare professions.

Thus, similar strategies can be employed in other areas of medical education in order to prepare health workers who are well trained to provide multidimensional health care to the patients.

Disclaimer: None to declare.

Conflict of Interest: None to declare.

Funding Sources: We received support from Department of Biological \& Biomedical Sciences.

\section{References}

1. Buring SM, Bhushan A, Broeseker A, Conway S, Duncan-Hewitt W, Hansen L, Westberg S. Interprofessional education: definitions, student competencies, and guidelines for implementation. Am J Pharm Educ 2009; 73: 59.

2. Thistlethwaite JE. Interprofessional education: implications and development for medical education. Educación Médica 2015; 16: 68-73.

3. Rehman SU, Ali F, Ahmad MU. Interprofessional Education: A Basic Need of Healthcare Department in Pakistan. Int J Biotechnol Wellness Industries 2017; 6: 55-63.

4. Birk TJ. Principles for Developing an Interprofessional Education Curriculum in a Healthcare Program. J Healthc Commun 2017; 2: 1.

5. World Health Organization. Framework for action on interprofessional education and collaborative practice. Geneva: WHO, 2010. 